\title{
POLICIAMENTO COMUNITÁRIO E PREVENÇÃO DO CRIME a visão dos coronéis da Polícia Militar
}

Resumo: O objetivo deste artigo é analisar a visão dos coronéis da Polícia Militar do Estado de São Paulo que participaram da direção da Comissão Estadual de Polícia Comunitária acerca do policiamento comunitário e da sua importância para a prevenção do crime.

Palavras-chave: polícia; crime; São Paulo.

Resumo: The aim of this article is to analyze the point of view of the colonels of the Military Police of São Paulo who participated in the State Commission on Community Policing with regard to the importance of preventive community policing.

Key words: police; crime; São Paulo.

$\mathrm{O}$ objetivo deste artigo é analisar a visão dos coronéis da Polícia Militar do Estado de São Paulo que participaram da direção da Comissão Estadual de Polícia Comunitária acerca do policiamento comunitário e da importância do policiamento comunitário para a prevenção do crime. Espera-se que a análise contribua para a compreensão do processo de implantação do policiamento comunitário e estimule o debate sobre o policiamento comunitário e a prevenção do crime no Estado de São Paulo.

A literatura sobre o policiamento comunitário mostra que a liderança exercida pelos chefes de polícia é um fator fundamental para a implantação e consolidação deste tipo de policiamento. Neste sentido, analisar a visão dos coronéis da Polícia Militar que participaram da direção da Comissão Estadual de Polícia Comunitária a respeito do policiamento comunitário e da prevenção do crime pode ajudar a compreensão do processo de implantação do policiamento comunitário, incluindo as dificuldades encontradas e os resultados alcançados, e das possibilidades de consolidação deste tipo de policiamento no Estado de São Paulo. Este artigo é um esforço inicial nesta direção. ${ }^{1}$

\section{POLICIAMENTO COMUNITÁRIO}

O policiamento comunitário é uma filosofia de policiamento que ganhou força nas décadas de 70 e 80 , quando as organizações policiais em diversos países da América do Norte e da Europa Ocidental começaram a promover uma série de inovações na sua estrutura e funcionamento e na forma de lidar com o problema da criminalidade. Em países diferentes, as organizações policiais promoveram experiências e inovações com características diferentes. Mas, algumas destas experiências e inovações são geralmente reconhecidas como a base de um novo modelo de polícia, orientada para um novo tipo de policiamento, mais voltado para a comunidade, que ficou conhecido como policiamento comunitário (Bayley; Skolnick, 2001; Skolnick; Bayley, 2002). ${ }^{2}$

Quatro inovações são consideradas essenciais para o desenvolvimento do policiamento comunitário (Bayley; Skolnick, 2001:224-232; Skolnick; Bayley, 2002:15-39): - organização da prevenção do crime tendo como base a comunidade;

- reorientação das atividades de policiamento para enfatizar os serviços não emergenciais e para organizar e mobi- 
lizar a comunidade para participar da prevenção do crime;

- descentralização do comando da polícia por áreas;

- participação de pessoas civis, não-policiais, no planejamento, execução, monitoramento e/ou avaliação das atividades de policiamento.

Estudos de processos de implantação do policiamento comunitário em diversos países apontam quatro fatores cruciais para a implantação e consolidação deste tipo de policiamento (Bayley; Skolnick, 2001:233-236):

- envolvimento enérgico e permanente do chefe com os valores e implicações de uma polícia voltada para a prevenção do crime;

- motivação dos profissionais de polícia por parte do chefe de polícia;

- defesa e consolidação das inovações realizadas;

- apoio público, da sociedade, do governo e da mídia.

Estes estudos apontam também as principais dificuldades para a implantação e consolidação do policiamento comunitário (Bayley; Skolnick, 2001:237-241; Skolnick; Bayley, 2002:71-92):

- a cultura tradicional da polícia, centrada na pronta resposta diante do crime e da desordem e no uso da força para manter a lei e a ordem e garantir a segurança pública;

- a expectativa ou a demanda da sociedade pela pronta resposta diante do crime e da desordem e pelo uso da força para manter a lei e a ordem e garantir a segurança pública;

- o corporativismo dos policiais, expresso principalmente através das suas associações profissionais, que temem a erosão do monopólio da polícia na área da segurança pública, e conseqüentemente a redução do emprego, do salário e dos benefícios dos policiais, além daquele decorrente do crescimento da segurança privada, e também o aumento de responsabilização dos profissionais de polícia perante a sociedade;

- a limitação de recursos que a polícia dispõe para se dedicar ao atendimento de ocorrências, a investigação criminal e a organização e mobilização da comunidade, especialmente se a demanda pelo atendimento de ocorrências e investigação criminal é grande (seja em virtude do número de ocorrências e crimes e/ou pela pressão do governo e da sociedade);

- a falta de capacidade das organizações policiais de monitorar e avaliar o próprio trabalho e fazer escolhas entre tipos diferentes de policiamento, levando em consideração sua eficácia, eficiência e legitimidade;
- a centralização da autoridade na direção das polícias, e a falta de capacidade da direção de monitorar e avaliar o trabalho das unidades policiais e profissionais de polícia; - as divisões e conflitos entre os policiais da direção e os da ponta da linha, entre policiais experientes e os policiais novos - e, no caso do Brasil, uma dificuldade adicional seria a divisão e conflito entre os policiais responsáveis pelo policiamento ostensivo na polícia militar e aqueles responsáveis pela investigação criminal na polícia civil;

- as divisões e conflitos entre a polícia e outros setores da administração pública;

- as divisões e conflitos entre grupos e classes sociais no interior da comunidade.

Diante destas dificuldades, há sempre o risco da oposição e da resistência a experiências e inovações visando a implementação do policiamento comunitário, dentro e fora da polícia. Mas há também um risco de que o policiamento comunitário venha a ser implantado como mais uma atividade especializada, atribuída a unidades e a profissionais especializados, pouco integrados às unidades responsáveis pelo patrulhamento, atendimento a ocorrências e investigação criminal. Ou mesmo o risco de que as unidades policiais, quando passam a ter a responsabilidade de fazer o policiamento comunitário, dêem menos valor às atividades de policiamento comunitário do que às atividades tradicionais de polícia. Por exemplo, designando para estas atividades menos tempo, menos recursos e/ou profissionais menos qualificados.

O papel das lideranças da polícia é, portanto, fundamental para iniciar e sustentar experiências e inovações visando à introdução do policiamento comunitário. Freqüentemente as dificuldades são apresentadas como uma explicação ou justificativa para a não implantação do policiamento comunitário ou para as limitações e deficiências no processo de implantação do policiamento comunitário. Há muitos casos em que a explicação ou justificativa é válida. Mas há também muitos casos em que a explicação ou justificativa simplesmente mascara a falta de visão, vontade e/ou capacidade de ação das lideranças da polícia.

\section{BRASIL - SÃO PAULO}

No Brasil, as organizações policiais começaram a promover experiências e inovações visando transformar sua estrutura e funcionamento, bem como sua relação com a 
sociedade durante a transição para a democracia, particularmente após a eleição direta dos governadores de estado em 1982. Em São Paulo, em 1985, durante o governo Franco Montoro, o governo do Estado começou a criar conselhos comunitários de segurança, existentes até hoje, que se reúnem regularmente e contam com a participação do delegado responsável pela Polícia Civil, do oficial responsável pela Polícia Militar, e representantes da comunidade.

No Rio de Janeiro, as idéias do policiamento comunitário começaram a ser introduzidas na polícia militar pelo Cel. PM Carlos Magno Nazareth Cerqueira, comandantegeral da Polícia Militar em 1983-84 e 1991-94, durante o governo Leonel Brizola. Neste período, a Polícia Militar do Rio de Janeiro produziu um caderno sobre o policiamento comunitário em 1993 (PMRJ 1993) e traduziu para o português o livro Policiamento Comunitário: Como Começar (Trojanowicz; Bucqueroux, 1994). Em 1993-94, a Polícia Militar, em parceria com a organização da sociedade civil Viva Rio, promoveu uma experiência de policiamento comunitário em Copacabana (Muniz et al., 1997).

No Estado de São Paulo, desde o início da década de 90, a Polícia Militar começou a promover iniciativas locais de mudanças organizacionais que apontavam na direção do policiamento comunitário, sendo freqüentemente citadas as experiências de Ribeirão Preto e Bauru. Mediante um conselho geral da comunidade que funciona junto ao comando-geral, a Polícia Militar chegou a elaborar um projeto para implantação do policiamento comunitário em 1993 (PMSP, 1993).

Em setembro de 1997, na seqüência do escândalo provocado por um caso de corrupção e violência policial na Favela Naval em Diadema, município da Região Metropolitana de São Paulo, e da eclosão de greves de policiais militares e civis em diversos estados do país, a Polícia Militar, sob a liderança do Cel. PM Carlos Alberto de Camargo, adotou o policiamento comunitário como filosofia e estratégia organizacional e criou, junto ao comando-geral, uma Comissão de Assessoramento para Implantação do Policiamento Comunitário, dirigida por coronéis da Polícia Militar e integrada por representantes de unidades da Polícia Militar e entidades da sociedade civil (Mesquita Neto, 1999; Mesquita Neto; Affonso, 1998). No ano 2000, a Polícia Militar reestruturou esta comissão, que passou a chamar-se Comissão Estadual de Polícia Comunitária, e criou o Departamento de Polícia Comunitária e Direitos Humanos, também vinculado ao comando-geral da Polícia, com o objetivo de aperfeiçoar e intensificar o processo de implantação do policiamento comunitário no Estado.

Ao lado das experiências locais e de outros estados brasileiros, as experiências de policiamento em outros países, particularmente nos Estados Unidos, no Canadá e no Japão foram analisadas e serviram como referência importante para os oficiais da Polícia Militar e para os membros da Comissão Estadual de Polícia Comunitária no processo de implantação do policiamento comunitário em São Paulo a partir de $1997 .^{3}$

Os coronéis que participam, ou participaram no passado, da direção da Comissão Estadual de Polícia Comunitária, são também comandantes de área e têm sob seu comando unidades operacionais da Polícia Militar. Estão, portanto, em uma posição privilegiada para promover a implantação do policiamento comunitário no Estado, influenciando a natureza das experiências e inovações promovidas pela Polícia Militar nesta área. Além disso, devido à sua experiência à frente da Comissão Estadual, estão em uma posição privilegiada para conhecer as possibilidades e as dificuldades para implantação deste tipo de policiamento, bem como os resultados alcançados pela Polícia Militar através da implantação deste tipo de policiamento.

\section{METODOLOGIA}

As fontes de dados para ao artigo foram as respostas de um grupo de sete coronéis a um questionário de 12 perguntas, aberto, preparado pelo autor. Foram inicialmente escolhidos para responder o questionário 14 coronéis, incluindo os 13 coronéis que já participaram ou ainda participam da direção da Comissão Estadual de Polícia Comunitária, e um coronel, recentemente promovido a este posto, que participou intensamente das atividades da Comissão Estadual e do Departamento de Polícia Comunitária e Direitos Humanos da Polícia Militar.

O Departamento de Polícia Comunitária e Direitos Humanos auxiliou o levantamento de informações fornecendo os telefones de contato de 12 dos 13 coronéis que já participaram ou ainda participam da direção da Comissão Estadual de Polícia Comunitária. Dos 14 coronéis procurados pelo autor, nove já estavam na reserva, um estava passando da ativa para a reserva e quatro ainda estavam na ativa.

Dez dos 14 coronéis foram efetivamente contatados e concordaram em responder o questionário. Três coronéis 
foram procurados, mas não retornaram ligações telefônicas e/ou não responderam os e-mails. O autor não pôde contatar, porque não teve acesso ao telefone ou $e$-mail, de um dos coronéis.

O autor enviou o questionário por escrito aos dez coronéis contatados, incluindo coronéis que atuavam na cidade de São Paulo e em cidades da Região Metropolitana de São Paulo e do interior do Estado. Um deles, após receber o questionário, disse não dispor das informações necessárias para respondê-lo. Dois outros não enviaram as respostas. Sete coronéis enviaram as respostas por escrito ao autor. A análise apresentada a seguir, portanto, reflete a visão de apenas um grupo de coronéis, não a visão do conjunto dos coronéis da Polícia Militar. Mas este é um grupo de coronéis que estiveram ou ainda estão diretamente envolvidos no processo de implantação do policiamento comunitário e têm conhecimento direto dos sucessos e fracassos, possibilidades e limites do policiamento comunitário no Estado.

O questionário e as respostas apresentadas pelos coronéis focalizaram os seguintes tópicos:

- os crimes que mais contribuem para a insegurança da população e suas causas;

- as ações para prevenção dos crimes relacionados;

- a eficácia do policiamento comunitário para prevenção dos crimes relacionados;

- a implantação e os resultados do policiamento comunitário em São Paulo;

- a consolidação e aperfeiçoamento do policiamento comunitário em São Paulo.

\section{CRIME E INSEGURANÇA}

$\mathrm{Na}$ visão dos sete coronéis da Polícia Militar que responderam o questionário, os crimes que mais contribuem para a insegurança da população no Estado de São Paulo são os crimes violentos, que atingem ou ameaçam atingir a vida e a integridade física das pessoas. Os crimes mais citados são o homicídio e o roubo, havendo referências explícitas ao roubo praticado com arma de fogo e ao roubo seguido de morte (latrocínio). Também são mencionados crimes cuja prática freqüentemente envolve grupos organizados, como o tráfico de drogas, contrabando, receptação, e prostituição infanto-juvenil.

O furto, crime praticado sem violência, mas cujo número de ocorrências registradas pela Polícia no Estado é superior ao número de ocorrências dos crimes praticados com violência mencionados acima, atingindo, portanto, um número maior de pessoas, foi citado como uma das principais fontes de insegurança por apenas um dos sete coronéis.

Questionados sobre as causas destes crimes, os coronéis apontam, em primeiro lugar, problemas econômicos, sociais, culturais, particularmente deficit na área da educação e na área do emprego e renda, que por sua vez são associados à ausência ou à fragilidade de políticas públicas nestas áreas. Dois coronéis apontam problemas de desestruturação familiar e, na esfera das atitudes e comportamentos individuais, o egoísmo e o consumismo, percebidos como atitudes e comportamentos estimulados pela mídia e associados à fragilização das leis e normas que regulam a vida em sociedade.

Os coronéis apontam também a impunidade, associada a problemas na aplicação da lei em decorrência de falhas na legislação e de deficiências nos sistemas de segurança pública e justiça criminal. Quatro coronéis fazem referências explícitas a problemas relacionados à atuação da polícia: um refere-se ao distanciamento entre a Polícia e a comunidade; outro à subnotificação de crimes; outro ao desaparelhamento da polícia; e outro ao crescimento da corrupção nas organizações dos sistemas de segurança pública e justiça criminal, associando este problema em parte ao crescimento do crime organizado e em parte a deficiências nos sistemas de controle interno e externo destas organizações.

Dois coronéis, atentos aos fatores situacionais que aumentam o risco de mortes violentas, apontam a disseminação das drogas e do álcool e das armas de fogo, associados ao crescimento do crime organizado, particularmente do tráfico de drogas, como fatores importantes para o aumento da criminalidade e da insegurança da população. Um coronel aponta a procura de recursos para compra de drogas como um fator importante para explicar o aumento de roubos e furtos, e a insegurança dos criminosos na prática de roubos e furtos, principalmente diante de uma reação da vítima, como fator responsável pela ocorrência de mortes violentas, registradas como homicídios ou latrocínios.

Um coronel aponta a falta de integração entre o governo federal, os governos estaduais e os governos municipais, e também a demagogia ou ideologia, na sociedade e no governo, como obstáculos ao desenvolvimento de políticas públicas para redução da criminalidade e melhoria da segurança pública. 


\section{PREVENÇÃO DO CRIME}

Para a prevenção dos crimes mencionados acima, os coronéis enfatizam a importância do fortalecimento das políticas públicas nas áreas econômica, social e cultural, particularmente na área da educação e na geração de emprego e renda, e também da redução da impunidade através de mudanças na legislação e do aperfeiçoamento da atuação das organizações dos sistemas de segurança pública e justiça criminal. Um coronel enfatiza a importância do desenvolvimento de políticas econômicas, sociais e culturais direcionadas a crianças, adolescentes e jovens como medida fundamental para evitar o recrutamento destes grupos pelo grupo crime organizado. Um coronel enfatiza a importância de políticas penitenciárias capazes de recuperar e promover a reinserção social dos criminosos.

Dois coronéis fazem referência explícita ao policiamento comunitário, em resposta à pergunta sobre o que poderia ser feito para a prevenção dos crimes que geram insegurança da população no Estado de São Paulo. Um coronel enfatiza a importância de estudos e análises visando identificar a natureza e as causas específicas da incidência de crimes em cada local, bairro ou cidade, a fim de que seja possível identificar a melhor estratégia de ação policial para cada caso.

$\mathrm{Na}$ visão do conjunto dos coronéis, deve haver maior integração das ações governamentais entre a União, os estados e os municípios, tanto na área das políticas econômicas, sociais e culturais quanto na área das políticas de segurança pública e das políticas criminais e penitenciárias. Um coronel enfatiza a importância da constituição de forças-tarefas para prevenção de crimes, a partir do município, com a participação de organizações policiais federais, estaduais e municipais, e acompanhamento de lideranças comunitárias. Outro coronel destaca a importância da integração das ações de organizações policiais, outras organizações governamentais e organizações da sociedade num mesmo Estado, bem como de intercâmbio de experiências entre organizações policiais em estados diferentes.

Um coronel faz referência à necessidade de valorização dos profissionais de polícia e outro faz referência à necessidade de aperfeiçoamento da formação e qualificação profissional dos policiais e da gestão das organizações policiais, visando diminuir a corrupção e a violência na polícia, aumentar a sua eficácia e eficiência e principalmente a sua legitimidade perante a sociedade.

\section{INTEGRAÇÃO DA POLÍCIA COM A COMUNIDADE}

Na visão dos coronéis, o policiamento é uma das atividades necessárias para a prevenção criminal, mas, isoladamente, tem efeitos limitados sobre a situação da segurança pública no Estado. Apesar destas limitações, o policiamento comunitário é considerado um tipo de policiamento capaz de contribuir para a melhoria da segurança pública, principalmente quando promover a integração de esforços da polícia e da comunidade no desenvolvimento de programas de prevenção do crime e gestão local da segurança pública.

As razões pelas quais o policiamento comunitário é considerado eficaz na prevenção do crime são variadas na visão dos coronéis. Primeiro, o policiamento comunitário é um tipo de policiamento voltado para a prevenção criminal, e não apenas para o atendimento de ocorrências e investigação criminal. Segundo, o policiamento comunitário promove a integração dos esforços da polícia e da comunidade na tentativa de eliminar as causas da violência. Terceiro, o policiamento comunitário integra a polícia e a comunidade na definição de prioridades em relação à prevenção criminal e permite a adequação da atuação da polícia às necessidades da comunidade. Quarto, o policiamento comunitário, pela aproximação entre a polícia e a comunidade, é um tipo de policiamento que permite a melhor administração e resolução de conflitos e problemas na sua origem. Quinto, o policiamento comunitário, também pela aproximação entre a polícia e a comunidade, é um tipo de policiamento que a aumenta a segurança e a motivação dos policiais e dos membros da comunidade no enfretamento da criminalidade.

Os coronéis apontam a redução da criminalidade e também o aumento da confiança da comunidade na polícia como as principais evidências da eficácia do policiamento comunitário, e acreditam que a efetiva implantação do policiamento comunitário contribui para a prevenção do crime e o aumento da sensação de segurança da população. Fazem referência a experiências internacionais, particularmente nos Estados Unidos, Canadá, Inglaterra e Japão, para mostrar que a efetiva implantação do policiamento comunitário contribui para a redução da criminalidade.

Em relação a experiências no Brasil, os coronéis mencionam avanços e retrocessos na tentativa de implantação do policiamento comunitário, mas apontam como exemplo de experiência bem-sucedida o policiamento comunitário implantado em algumas regiões da cidade de São 
Paulo (Jardim Ângela, Belém, Centro, Brás, Santana, Brooklin, Higienópolis, Favela Pantanal e Favela Alba), Santo André (Sacadura Cabral), Ribeirão Preto (Oeste), Bauru, Presidente Prudente, Andradina, Araraquara, São José dos Campos, Jundiaí e Santos (Campo Grande).

\section{IMPLANTAÇÃO E RESULTADOS}

Em relação à adoção do policiamento comunitário como filosofia e estratégia organizacional pela Polícia Militar em 1997, os coronéis fazem referência à influência de três fatores, que podem ser considerados complementares.

O primeiro diz respeito à busca da excelência por parte da Polícia Militar, a partir da incorporação de lições de experiências locais e de experiências internacionais de policiamento comunitário. Outro exemplo desta busca da excelência, paralelo e complementar à adoção do policiamento comunitário, seria a adoção do programa da qualidade pela Polícia Militar.

O segundo diz respeito à busca de uma nova filosofia e estratégia organizacional por parte da Polícia Militar, mais centrada em ações de natureza preventiva, que valorizasse o policiamento ostensivo. Esta busca aconteceria após o fracasso de um projeto denominado "rádio patrulhamento padrão", devido a não participação da comunidade no projeto e à pressa em desenvolvê-lo por razões políticas, e, especialmente, após o escândalo e a cobrança de mudanças na estrutura e no funcionamento da polícia na seqüência da denúncia de um caso de corrupção e violência policial na Favela Naval, em Diadema, cidade da Região Metropolitana de São Paulo.

Um terceiro fator mencionado pelos coronéis diz respeito ao processo de organização e mobilização da sociedade e à busca pela Polícia Militar de mudanças organizacionais e operacionais, particularmente no seu relacionamento com a sociedade, visando dar respostas a novas expectativas da sociedade e integrar esforços da polícia e da sociedade na direção de objetivos comuns.

Há, entretanto, visões diferentes sobre a natureza do policiamento comunitário. Na visão de um dos coronéis, o policiamento comunitário seria um tipo de policiamento que reforça idéias e práticas que sempre existiram na polícia, através de uma maior aproximação entre a polícia e a comunidade. Na opinião de outro coronel, entretanto, o policiamento comunitário seria uma solução emergencial, diante da situação de abandono de muitas comunidades, até que seja possível a implementação de políticas econômicas, sociais e culturais de maior alcan- ce, mais do que uma nova filosofia e estratégia organizacional da Polícia Militar.

Na visão dos coronéis, o policiamento comunitário pode ser considerado implantado no Estado, mas precisa de ajustes e aperfeiçoamentos e ainda não está consolidado. Os coronéis enfatizam a importância da difusão de informações sobre a filosofia de policiamento comunitário na Polícia Militar através de normas internas e cursos de formação e aperfeiçoamento profissional. Enfatizam também o estabelecimento de bases de polícia comunitária, e a formação de parcerias entre a Polícia Militar e a comunidade para a melhoria da segurança pública em áreas de maior incidência de crimes.

Por outro lado, alguns coronéis registram dúvidas sobre o enraizamento dos princípios de polícia comunitária. $\mathrm{Na}$ opinião de um coronel, o modelo tradicional de policiamento ainda se encontra fortemente arraigado na prática policial. Outro coronel diz que o modelo de tradicional de policiamento muitas vezes se mantém sob a roupagem do policiamento comunitário. Dois coronéis dizem que o policiamento comunitário ainda é muito dependente das iniciativas individuais de profissionais de polícia.

Os coronéis apontam algumas dificuldades para a implantação e consolidação do policiamento comunitário. Estas dificuldades incluem a falta de apoio por parte de setores do governo, da sociedade e mesmo da polícia, muitas vezes atribuído ao desconhecimento das características do policiamento comunitário, e especialmente à idéia de que o policiamento comunitário implica o favorecimento ou tratamento especial dos setores da comunidade que colaboram com a polícia e/ou de que o policiamento comunitário reduz a capacidade de ação repressiva da polícia. Incluem também a resistência de oficiais e/ou praças da Polícia Militar, e também dos policiais civis, decorrentes da cultura tradicional da polícia, e da crença de que o policiamento comunitário é um fenômeno passageiro. Estes fatores contribuiriam para a insuficiência dos recursos humanos e materiais direcionados para o policiamento comunitário.

Os coronéis apontam ainda dificuldades de gestão, incluindo planejamento, execução, monitoramento e avaliação do processo de implantação do policiamento comunitário, que deixam o processo de implantação, em grande parte, na dependência das idéias e interesses dos responsáveis por cada unidade policial e, assim, aumentam o risco de desvios na implantação deste tipo de policiamento. Um problema específico nesta área, citado por dois coronéis, é a rotatividade dos policiais e a difi- 
culdade de fixar os policiais em uma função ou área, em todos os níveis da organização. Outro problema é a pressa na implantação do policiamento comunitário, devido a razões políticas, sendo que, na visão de quase todos, a implantação do policiamento comunitário é um processo lento e de longo prazo. Outra dificuldade mencionada ainda é a diversidade de situações locais e as particularidades de cada comunidade, que exigem estilos diferentes e estratégias diferentes de implantação do policiamento comunitário.

$\mathrm{Na}$ esfera local, uma dificuldade seria a adequada compreensão das necessidades da comunidade em matéria de segurança pública, por parte da polícia e da comunidade, a partir da troca de informações, do conhecimento dos fatos, para definição consensual, não unilateral, dos procedimentos a serem adotados pela polícia e pela comunidade para prevenção do crime.

Apesar destas dificuldades, os coronéis consideram bem-sucedido o processo de implantação do policiamento comunitário no Estado e apontam, como principais resultados da implantação deste tipo de policiamento, a aproximação entre a Polícia Militar e a comunidade e a formação de parcerias entre as mesmas para o desenvolvimento de programas de prevenção do crime. Os coronéis apontam também a redução da criminalidade e o aumento da sensação de segurança da população nos locais em que o policiamento comunitário foi implantado como um resultado deste tipo de policiamento. Um coronel chegou a relacionar a implantação do policiamento comunitário à estabilização e até redução das taxas de diversos crimes no Estado a partir do ano 2000. Ao mesmo tempo, um coronel observa que, nos locais onde o policiamento comunitário é implantado, a polícia passa a ser mais procurada pela população e há um aumento do número de registros de ocorrências de alguns crimes que antes deixavam de ser registrados.

\section{CONSOLIDAÇÃO E APERFEIÇOAMENTO}

Para os coronéis que responderam o questionário, a consolidação e o aperfeiçoamento do policiamento comunitário constituem objetivo desejável, mas dependente de uma série de fatores, alguns deles dentro e outros fora do alcance da Polícia Militar.

Um fator é a ação constante e determinada das lideranças da polícia no fortalecimento do policiamento comunitário, particularmente na formação e aperfeiçoamento profissional dos policiais, na ampliação dos recursos humanos e materiais destinados ao policiamento comunitário, e no monitoramento e avaliação dos resultados das experiências de policiamento comunitário. Um coronel enfatizou a importância do fortalecimento do papel do comandante de companhia como gestor local da segurança pública. Nesta visão, os comandantes de companhia seriam responsáveis pela resolução dos problemas e melhoria da segurança pública, a partir da adequada utilização dos recursos policiais e comunitários disponíveis na área, e os resultados obtidos seriam constantemente monitorados e avaliados pelo comando da polícia.

Outro fator é o engajamento efetivo da polícia e da comunidade no policiamento comunitário, na discussão e desenvolvimento de práticas de policiamento comunitário e programas de prevenção do crime e da violência. Neste sentido, foi também ressaltada a importância da sensibilização da mídia e de lideranças da polícia e da comunidade, e de campanhas para difusão de informação sobre as características do policiamento comunitário e divulgação de experiências bem-sucedidas de policiamento comunitário. Um coronel mencionou a necessidade de implantação de bases comunitárias em todo o Estado, ressaltando, entretanto, que a implantação não deve imobilizar os policiais, uma vez que os policiais devem se aproximar da comunidade para desenvolver projetos voltados para a prevenção do crime.

Um terceiro fator é um engajamento do governo estadual, do governo federal e dos governos municipais, incluindo um maior envolvimento na implantação da polícia comunitária da polícia civil, polícia técnico-científica e outras agências do governo estadual, e parcerias com as guardas municipais.

\section{CONCLUSÃO}

O objetivo deste artigo é principalmente apresentar a visão de um grupo de coronéis da Polícia Militar sobre o policiamento comunitário e a prevenção do crime no Estado de São Paulo. O artigo não teve por objetivo explicar ou interpretar, e muito menos comentar, criticar ou elogiar, a visão dos coronéis. Mas pretendeu estabelecer relações entre a visão dos coronéis e as idéias presentes na literatura sobre o policiamento comunitário, e contribuir para a compreensão do processo de implantação deste tipo de policiamento no Estado de São Paulo.

Esta breve apresentação da visão dos coronéis mostra a complexidade do processo de implantação e consolidação do policiamento comunitário, bem como a diversida- 
de de pontos de vistas existente na Polícia Militar em relação a este processo. Mostra também que, na visão dos coronéis, apresentada no artigo, o policiamento comunitário foi implantado no Estado de São Paulo devido ao empenho de lideranças e grupos situados no interior da Polícia Militar, com apoio de organizações e grupos da sociedade civil, mas sem muito apoio da Polícia Civil e de outras organizações do governo estadual, das prefeituras municipais e do governo federal. De acordo com esta visão, o maior envolvimento do governo estadual e das prefeituras municipais, com apoio do governo federal, é percebido como fator importante para a consolidação e o aperfeiçoamento do policiamento comunitário e a prevenção do crime no Estado.

Entretanto, na visão dos coronéis, as dificuldades na implantação do policiamento comunitário derivam não apenas de fatores externos, mas também de fatores internos à Polícia Militar, que estão freqüentemente relacionados aos externos, sendo que muitas dificuldades apontadas pelos coronéis coincidem com as dificuldades apontadas pela literatura sobre o policiamento comunitário. Entre as dificuldades de natureza interna à polícia citadas pelos coronéis, chama atenção a dificuldade de gestão da organização, particularmente para planejar, implementar, monitorar e avaliar uma mudança organizacional, que implica uma certo grau de descentralização do comando, com a participação de policiais de todos os setores da organização e lideranças da comunidade. Neste sentido, parece importante procurar compreender as razões pelas quais a Polícia Militar implementa de forma paralela e quase segregada os processos de implantação do policiamento comunitário e da gestão pela qualidade, apresentados como exemplo da busca de excelência por um dos coronéis, e, eventualmente, verificar a possibilidade de integrar os dois processos em benefício do aperfeiçoamento da atuação da polícia na prevenção do crime e da melhoria da segurança pública.

\section{NOTAS}

1. O autor agradece a colaboração do Departamento de Polícia Comunitária e Direitos Humanos da Polícia Militar do Estado de São Paulo e dos sete coronéis que contribuíram para a realização deste estudo, respondendo a perguntas de um questionário sobre policiamento comunitário e prevenção do crime: Cel. Res. PM Carlos Adelmar Ferreira, Cel. Res. PM Cid Monteiro de Barros, Cel. Res. PM Luis Francisco Coscione, Cel. Res. PM Rui César Melo, Cel. PM Noel Miranda de Castro, Cel. PM Renato Penteado Perrenoud e Cel. PM Rubens Casado. $\mathrm{O}$ autor agradece também a atenção dos outros coronéis que parti- cipam ou participaram da direção da Comissão Estadual de Polícia Comunitária, que foram contatados, mas por razões diversas não puderam responder o questionário dentro do prazo solicitado.

2. Um estilo de policiamento comunitário centrado no estabelecimento de postos de polícia denominados Koban foi implantado no Japão após a $2^{\text {a }}$ Guerra Mundial, resultado da combinação de um modelo tradicional de polícia desenvolvido no Japão no século XIX e ideais democráticos norte-americanos (Bayley; Skolnick, 2002:52). Entretanto, foi apenas nas décadas de 70 e 80 , com o desenvolvimento de experiências de policiamento na América do Norte e Europa Ocidental que esse tipo de policiamento tornou-se mais conhecido internacionalmente.

3. O Núcleo de Estudos da Violência da Universidade de São Paulo e o Centro de Pesquisa e Educação em Direitos Humanos da Universidade Ottawa desenvolveram um programa de intercâmbio internacional através do qual policiais civis e militares e líderes comunitários paulistas realizaram visitas ao Canadá e policiais e líderes comunitários canadenses realizaram visitas ao Brasil, para trocar informações e experiências na área do policiamento comunitário e do controle externo da polícia. A Polícia Militar do Estado de São Paulo desenvolveu um programa de intercâmbio com a Polícia Nacional do Japão, através do qual policiais japoneses realizam visitas ao Brasil e policiais militares brasileiros realizam visitas ao Japão para trocar informações e experiências na área do policiamento comunitário. A experiência dos Estados Unidos ficou conhecida principalmente através do livro Policiamento Comunitário: Como Começar (Trojanowicz; Bucqueroux, 1994), traduzido para o português pela Polícia Militar do Rio de Janeiro e reeditado pela Polícia Militar de São Paulo em 1999.

\section{REFERÊNCIAS BIBLIOGRÁFICAS}

BAYLEY, D.H.; SKOLNICK, J.H. Nova Policia: inovações nas policias de seis cidades norte-americanas. Tradução de Geraldo Gerson de Souza. São Paulo: Editora da USP, 2001.

MESQUITA NETO, P. de. Policiamento Comunitário: a experiência em São Paulo. Revista Brasileira de Ciências Criminais, São Paulo, Instituto Brasileiro de Ciências Criminais, ano 7, n.25, p.281-292, jan./mar. 1999.

MESQUita Neto, P. de.; AFFONSO, B. Policiamento Comunitário: a experiência em São Paulo. São Paulo: Núcleo de Estudos da Violência da Universidade de São Paulo, 1998. Manuscrito.

MUNIZ, J. et al. Resistências e dificuldades de um programa de policiamento comunitário. Tempo Social, São Paulo, Departamento de Sociologia da Universidade de São Paulo, v.9, n.1, p. 197-213, maio 1997.

PMRJ. Polícia Militar do Estado do Rio de Janeiro. Cadernos de Polícia - Policiamento Comunitário. Rio de Janeiro: PMRJ, 1993.

PMSP. Polícia Militar do Estado de São Paulo. Projeto Polícia Comunitária: implantação de modelo e ação educativa. São Paulo: PMSP, Conselho Geral da Comunidade, 1993.

SKOLNICK, J.H.; BAYLEY, D.H. Policiamento Comunitário. Tradução de Ana Luísa Amêndola Pinheiro. São Paulo: Editora da USP, 2002.

TROJANOWICZ, R.; BUCQUEROUX, B. Policiamento Comunitário: como começar. Tradução Mina Seinfeld de Carakushansky. Rio de Janeiro: Polícia Militar do Estado do Rio de Janeiro, 1994. Reeditado pela Polícia Militar do Estado de São Paulo, 1999.

Paulo de Mesquita Neto: Pesquisador do Núcleo de Estudos da Violência da Universidade de São Paulo, Secretário-Executivo do Instituto São Paulo Contra a Violência (pmesquit@usp.br). 